\title{
EFETIVIDADE DOS DIREITOS FUNDAMENTAIS DO TRABALHADOR E A REFORMA TRABALHISTA
}

\author{
Nágila de Jesus de Oliveira Quaresma* \\ Patricia Kristiana Blagitz Cichovski**
}

\begin{abstract}
RESUMO: Estudo que analisa os entraves à efetividade dos direitos fundamentais do trabalhador, previstos na Constituição Federal de 1988, em especial, após a publicação da reforma trabalhista de 2017. O novo marco legislativo das relações laborais trouxe profundas alterações que distanciaram mais ainda a possibilidade de concretização dos direitos fundamentais dos trabalhadores. O problema de pesquisa consiste em identificar quais os fatores que representam embaraços à efetividade das normas constitucionais trabalhistas, principalmente, após a vigência da lei n. ${ }^{\circ} 13.467 / 2017$. Utilizamos como metodologia a análise teórico normativa e o emprego de dados, quando necessário, além das pesquisas histórica e analítica.
\end{abstract}

Palavras-chave: Constituição; Direitos fundamentais; Efetividade; Reforma Trabalhista; Trabalhador.

\section{EFFECTIVENESS OF FUNDAMENTAL RIGHTS OF WORKER AND LABOR REFORM}

\begin{abstract}
This study analyzes the obstacles to the effectiveness of the fundamental rights of the workers, foreseen in the Federal Constitution of 1988, in particular, after the publication of the labor reform of 2017. The new legislative framework of labor relations brought profound changes that further distanced the possibility of realization fundamental rights of workers. The research problem is to identify the factors that represent embarrassment to the effectiveness of labor constitutional norms, especially after the reform. We use as methodology the theoretical normative analysis and the use of data, when necessary, in addition to historical and analytical research.
\end{abstract}

Keywords: Constitution; Fundamental Rights; Effectiveness; Labor Reform; Worker.

\footnotetext{
* Mestranda em Direito, Políticas Públicas e Desenvolvimento Regional pelo Centro Universitário do Pará (CESUPA). Juíza do Trabalho. E-mail: nagiladejesus@icloud.com

** Doutora em Direito do Estado, Professora do Programa de Pós-Graduação em Direito do Centro Universitário do Pará (CESUPA). Diretora de Ensino e Pesquisa da Escola da Magistratura do Estado do Pará. E-mail: p-blagitz@uol.com.br
} 


\section{INTRODUÇÃO}

A Constituição de 1988 alçou o valor social do trabalho a fundamento da República, passando a figurar em um seleto rol ao lado da dignidade da pessoa humana e de outros valores democráticos. Cresceu a esperança na melhoria da condição social dos trabalhadores, na diminuição das desigualdades e na inclusão social de significativa parcela da população brasileira.

Alguns segmentos de trabalhadores, tidos como uma espécie de capitis diminutio, a exemplo dos domésticos e dos rurais que estavam, inexplicavelmente, excluídos de muitos benefícios trabalhistas, foram encampados pela novel normatização constitucional. Além do que outros direitos também foram ampliados àqueles já existentes, bem como agregados às categorias dos trabalhadores avulsos, em clara manifestação de valorização do trabalho. No plano coletivo não foi diferente. As entidades sindicais ganharam proeminência e a liberdade sindical representou um avanço na atuação dos trabalhadores organizados, vedando-se a interferência estatal. Assegurou-se o direito de greve, competindo aos trabalhadores decidirem sobre a conveniência de deflagrar o movimento paredista.

O cenário edificado pela alcunhada Constituição Cidadã era alvissareiro, de renovação e nitidamente centrado na pessoa humana. Ocorre, porém, que muito desses novos direitos careciam de regulamentação por lei infraconstitucional e, à medida que se seguiram os anos, a postergação se impusera como estratégia de setores conservadores para adiar ao máximo a efetivação das promessas constitucionais. Em um país, como o Brasil, marcado pela intensa desigualdade social, a efetividade de direitos sempre esteve no centro das atenções, mormente pela importância que o trabalho constitui para a maioria da população e, consequentemente, para a construção do solidarismo constitucional.

Por outro lado, avanços houve, ainda que em passos mais lentos do que o desejado. A partir de 2002, as forças políticas convergiam para alcance de um nível satisfatório de concretização dos direitos fundamentais sociais e algumas importantes conquistas chegaram a ser verificadas. Entretanto, as melhorias obtidas sofreram sensíveis marcha em contrário, pois não tempo depois, nos deparamos com alterações infra-constitucionais, sendo a de maior proporção, instituída pela denominada Reforma Trabalhista, Lei n. ${ }^{\circ} 13.467 / 2017$, que, em parte, pretende desconstruir o arcabouço principiológico de valorização do trabalho.

O problema de pesquisa consiste em analisar como a efetividade dos direitos fundamentais do trabalhador, previstos na $\mathrm{CRFB} / 88$, enfrentou, no decorrer dos anos, diversas 
dificuldades para sua concretização, principalmente após as alterações recentes, como a reforma trabalhista e seus reflexos para a preservação dos postulados sociais instituídos em 1988, consistindo essa análise o objetivo precípuo do estudo.

Imbuídos desse intuito, discorreremos sobre os direitos garantidos aos trabalhadores pelo Constituinte de 1988, bem como os percalços enfrentados ao longo dos anos para sua efetivação. Em seguida, destacaremos o impacto da reforma trabalhista de 2017 no contexto da problematização da efetividade. Por fim, apontaremos as perspectivas decorrentes do cenário e possíveis soluções. Utilizaremos como metodologia a análise teórico normativa, bem como o emprego de dados, quando necessário, além das pesquisas histórica e analítica.

\section{A PRINCIPIOLOGIA E A EXPANSÃo SOCIAL EMOLDURADA PELA CARTA POLÍTICA DE 1988}

A Constituição Federal de 1988 instituiu o Estado Democrático de Direito, anunciando e traçando para o país novo tratamento normativo e principiológico. Na esteira de solidificar a escolha, designou como uns de seus fundamentos a dignidade da pessoa humana, a cidadania e o valor social do trabalho, com os objetivos de construir uma sociedade livre, justa e solidária, garantir o desenvolvimento nacional, erradicar a pobreza e a marginalização e reduzir as desigualdades sociais e regionais, além de promover o bem de todos, sem preconceitos de origem, raça, sexo, cor, idade e quaisquer outras formas de discriminação.

A estrutura principiológica do constituinte recai, substancialmente, na valorização da pessoa humana e sua dignidade, ideia matriz que enfeixa grande parte dos direitos enumerados ao longo de seus 250 artigos, além dos 114 artigos constantes no ADCT (Ato das Disposições Constitucionais Transitórias). Para melhor elucidação do fundamento constitucional apontado, importante debruçamos sobre o conceito de dignidade e, nessa tarefa, pela clareza de seus imperativos nos valemos dos nortes traçados pelo filósofo Immanuel Kant para quem

No reino dos fins tudo tem ou um preço ou uma dignidade. Quando uma coisa tem um preço, pode-se pôr em vez dela qualquer outra coisa como equivalente; mas quando uma coisa está acima de todo o preço, e portanto não permite equivalente, então tem ela dignidade.

[...]; aquilo porém que constitui a condição só graças a qual qualquer coisa pode ser um fim em si mesma, não tem somente um valor relativo, isto é um preço, mas um valor íntimo, isto é dignidade. (KANT, 2011, p. 82).

Extraímos, ainda, das lições de Kant, em sua obra Fundamentação da Metafísica dos Costumes, o que vem de encontro à dignidade, precisamente, a instrumentalização, a 
coisificação, a mercantilização tanto do outro, quanto de si. $\mathrm{O}$ respeito à dignidade consistiria em tratarmos a nós mesmos e aos outros como fins em si mesmos, pela simples razão de possuirmos valores intrínsecos à humanidade, próprias do ser racional (KANT, 2011, p. 80).

Trabalhando com a mesma ideia de dignidade, Sarlet esclarece:

[...] Esta, portanto, compreendida como qualidade integrante e irrenunciável da própria condição humana, pode (e deve) ser reconhecida, respeitada, promovida e protegida, não podendo, contudo (no sentido ora empregado) ser criada, concedida ou retirada (embora possa ser violada), já que existe em cada ser humano como algo que lhe é inerente (SARLET, 2006, p. 41-42).

Portanto, a presença da dignidade, inerente à pessoa humana será o pressuposto, a pedra angular dos direitos humanos e, consequentemente, dos direitos sociais fundamentais do trabalhador e esse norte vai modificar por completo a visão reducionista de direitos, espraiando a todos a necessidade de conceder o máximo valor ao outro individualmente e como membro de uma coletividade.

Com efeito, tendo a dignidade como epicentro normativo constitucional, mister implementar um arcabouço legislativo que possa alcançar sucesso no mundo dos fatos.

[...]A norma constitucional não tem existência autônoma em face da realidade. A sua essência reside na sua vigência, ou seja, a situação por ela regulada pretende ser concretizada na realidade.(HESSE, 1991, pág. 14-15).

Barroso elucida que efetividade deve ser entendida como

[...] a realização do Direito, a atuação prática da norma, fazendo prevalecer no mundo dos fatos os valores e interesses por ela tutelados. Simboliza a efetividade, portanto, a aproximação, tão íntima quanto possível, esse dever ser normativo e o ser da realidade social. [...] (BARROSO, 2005, p.40)

A efetividade, portanto, é essencial para a promoção da dignidade.

A Constituição promoveu mudanças visando a alcançar esse desiderato, v.g., ao conceder aos empregados domésticos tratamento jurídico mais isonômico. Impende destacar que essa espécie de trabalhador permaneceu em uma espécie de limbo jurídico, pois, expressamente, estavam excluídos das normas protetivas constantes na CLT (art. $7^{\text {o } ~ " a ") ~ e ~}$ apenas com a Lei $\mathrm{n}^{\circ}$ 5859/72 lhes foram conferidos três parcos direitos (anotação da CTPS, férias de 20 dias e inscrição obrigatória na previdência social). Tempos depois, foi-lhes estendido o benefício do vale transporte (Leis ns. 7418/85 e 7619/87 e Decreto n. 95.247/87). Nada mais que singelos quatro direitos.

Para dimensionar o impacto provocado pela $\mathrm{CRFB} / 88$, foram garantidos aos empregados domésticos, os seguintes direitos: salário mínimo, irredutibilidade de salário, $13^{\circ}$ 
salário, repouso semanal remunerado, preferencialmente aos domingos, gozo de férias anuais remuneradas acrescidas de $1 / 3$ do salário, licença à gestante remunerada, sem prejuízo do emprego, licença paternidade, aviso prévio de no mínimo trinta dias e aposentadoria. Essa gama protetiva representava uma revolução silenciosa para a categoria que, como já mencionado, vivia em situação de inconcebível marginalidade jurídica.

Após a CRFB/88, outros direitos foram concedidos por leis esparsas e, principalmente, pela EC 72/2013 que estendeu vários importantes direitos que representavam anseios antigos, como a histórica conquista de limitação da jornada de trabalho, igualando aos demais trabalhadores, não superior a 8 horas diárias e 44 horas semanais, além da garantia do pagamento de horas extras com adicional de 50\% sobre a hora normal. Houve, ainda, a extensão do adicional noturno, a tutela à saúde e segurança no trabalho, obrigatoriedade do FGTS e, consequente percepção do seguro desemprego.

Similar tratamento jurídico outorgado aos domésticos, anterior à CRFB/88, era dispensado aos trabalhadores rurais que, da mesma forma, foram expressamente excluídos das regras protetivas da CLT (art. 7 " "b”), a exceção do salário mínimo, das férias e do aviso prévio. É certo que o Estatuto do Trabalhador Rural (Lei n. ${ }^{\circ}$ 4214/63) e, posteriormente, a Lei n. ${ }^{\circ}$ 5889/73 elasteceram os direitos dos rurícolas, no entanto, apenas a CRFB/88 no caput de seu art. $7^{\mathbf{o}}$ conferiu igualdade de tratamento jurídico com os trabalhadores urbanos, ao dispor que "são direitos dos trabalhadores urbanos e rurais, além de outros que visem à melhoria de sua condição social". O mesmo fenômeno jurídico expansionista, assentado no princípio da igualdade, garantiu aos trabalhadores avulsos idêntico tratamento dos urbanos ( art. $7^{\circ}$, inciso XXXIV).

A Carta Magna de 1988 não tratou apenas de estender direitos às categorias, até então não beneficiadas por uma gama de normas protetivas relacionadas ao trabalho. Ampliou e criou outros importantes direitos, como a dilação para 120 da licença previdenciária para as empregadas gestantes (art. $\left.7^{\circ}, \mathrm{XVIII}\right)$, bem como assegurou a garantia de emprego de até cinco meses após o parto (art. 10, II, “b”, previsto no ADCT), majorou de 1 para 5 dias a licença paternidade ( $\operatorname{art} .7^{\circ}$ XIX e art. 10, parágrafo $1^{\circ}$ do ADCT) e de 8 para 30 dias o prazo mínimo do aviso prévio (art. $\left.7^{\circ}, \mathrm{XXI}\right)$, garantiu a participação nos lucros ou resultados (PLR) e procurou sinalizar para a democratização da gestão das empresas com a possibilidade de participação dos trabalhadores $\left(7^{\circ}, \mathrm{XI}\right)$.

A pletora de direitos alcançou, inclusive, o instituto da prescrição ao majorar de dois para cinco anos o lapso prescricional da pretensão de parcelas a serem vindicadas no curso do 
contrato de trabalho (art. $7^{\circ}$ XXXIX, "a"); uniformizou o regime jurídico do FGTS e aumentou em quatro vezes a multa rescisória (art. 10, I do ADCT).

$\mathrm{Na}$ seara do direito do trabalho coletivo não foi diferente. Embora mantidos aspectos antidemocráticos como a unicidade e enquadramento sindicais, a Carta Constitucional assegurou a liberdade associativa e sindical, eliminando a nefasta e comprometedora interferência do Poder Executivo ( art. $8^{\circ}$, I e II), incentivou a negociação coletiva com participação obrigatória dos sindicatos dos trabalhadores nos acordos ou convenções coletivas (art. $7^{\circ}, \mathrm{XXVI)}$, além de propiciar ambiente favorável para ajuizamento de ações coletivas, seja através do instituto da substituição processual pelos sindicatos (art. $8^{\circ}$, III ), seja pelo patrocínio do Ministério Público do Trabalho (art.127 caput e art. 129, II, III e IX). Além do que foi garantido o direito de greve, competindo aos trabalhadores decidir sobre a oportunidade de exercê-lo e sobre os interesses que devam por meio dele defender (art. $9^{\circ}$ ).

Não menos importante, ao contrário, decisivo no contexto social de valorização social do trabalho, a Constituição Cidadã determinou o melhor aparelhamento e interiorização da Justiça do Trabalho em primeiro e segundo graus (art. 112) e conferiu significativa ampliação de poderes e atuação ao Ministério Público do Trabalho (art.127 caput e art. 129, II, III e IX), tanto na esfera judicial como na extrajudicial, conferindo-lhe a defesa dos interesses coletivos e individuais homogêneos dos trabalhadores.

$\mathrm{O}$ arcabouço normativo apontado elucida as vigas mestras para a construção do Estado Democrático de Direito que, ao olhar o homem como um fim em si mesmo e, consequentemente, combater o uso de sua força de trabalho como mero instrumento, reforça a importância concedida ao valor trabalho para a inclusão social e redução das desigualdades sociais. Nesse sentido, Delgado pontua que:

O Estado Democrático de Direito concebido pela nova Constituição funda-se em um
inquebrável tripé conceitual: a pessoa humana, com sua dignidade; a sociedade
política, concebida como democrática e inclusiva; e a sociedade civil, também
concebida como democrática e inclusiva. Ora, na conformação de todos os elementos
desse tripé, em especial a garantia de efetiva dignidade à pessoa humana, além da
garantia de efetivação das ideias de democratização e do caráter inclusivo da
sociedade política e da sociedade civil, ostenta papel imprescindível o Direito do
Trabalho (DELGADO, 2018, p. 65).

Portanto, é inquestionável a consagração e significativa ampliação dos direitos fundamentais do trabalhador. Os pilares fincados ecoavam a esperança de melhoria das condições sociais, inclusão social e diminuição das desigualdades sociais. O apanhado normativo instituído desenhava um cenário de crescente progressividade social trabalhista, mormente porque a própria Constituição de 1988 fez questão de ressaltar no caput do art. $7^{\circ}$ 
que os direitos apresentados não eram taxativos, utilizando-se para tanto da expressão "além de outros que visem à melhoria de sua condição social."

Como visto, o farol apontado pela Constituição guiava para o alcance das melhorias sociolaborativas, com o nítido objetivo de construir uma sociedade mais justa e solidária. No entanto, as idiossincrasias dos momentos políticos e econômicos desenharam outra realidade que será abordada no tópico seguinte.

\section{O CENÁRIO JURídico POSTERIOR À CONSTITUIÇÃo. A REFORMA TRABALHISTA}

Os anos que se seguiram, após a publicação da Constituição Federal de 1988 foram marcados pela adoção de medidas políticas e econômicas que privilegiaram a liberação dos mercados, privatizações e flexibilização de direitos trabalhistas. No decorrer dos anos 90, pouco ou nada se viu que efetivassem os direitos fundamentais na área trabalhista. Embora alguns avanços tenham sido pontualmente conquistados, o que se disseminou foram diversas formas de precarização do trabalho subordinado como o fenômeno da terceirização, o contrato a tempo parcial, a pejotização ${ }^{1}$ que tinham claro intuito reducionista dos direitos sócio laborativos.

De fato, logo após o surgimento da Constituição de 1988 , fortaleceu-se, no País, no
âmbito oficial e nos meios privados de formação de opinião pública, um pensamento
estratégico direcionado à total desarticulação das normas estatais trabalhistas, com a
direta e indireta redução dos direitos e garantias laborais. Ou seja, mal se iniciara a
transição democrática do Direito do Trabalho (já guardando, em si mesma, algumas
contradições), a ela se acoplava uma proposta de desarticulação radical desse ramo
jurídico especializado. Nesse quadro, a maturação do processo democratizante
comprometia-se em face do assédio da proposta extremada de pura e simples
desarticulação de todo o ramo jurídico protetivo (DELGADO, 2018, p. 135).

Há que se ponderar também que se vivia um momento de expansão de um modelo de estado mínimo, neoliberal, com o crescente fenômeno da globalização que

A globalização norteada pelo neoliberalismo ao promover as integrações das economias mundiais, também impõe uma redução na atuação estatal. Em verdade, estabelece como diretriz um Estado-Mínimo em contraposição ao Estado-Providência. A autonomia privada ressurge com força, criticando a intervenção estatal, que segundo este pensamento, tem propiciado obstáculos para o crescimento econômico. Este contraste entre um Estado, ainda interventor, que sofre reduções, limitações e privatizações provoca uma crise particular do Estado(OLIVEIRA, 2006, P. 01)

O foco prioritário era o mercado e tudo que ele poderia supostamente trazer de progresso

1 Termo utilizado pela jurisprudência para se referir a contratação de trabalhador subordinado pessoa física como prestador autônomo de serviços com a utilização do subterfúgio de constituição de uma pessoa jurídica (PJ).

Rev. de Direitos Fundamentais nas Relações do Trabalho, Sociais e Empresariais | e-ISSN: 2525-9903 | Porto Alegre | v. 4 | n. 2 | p. $62-82$ | Jul/Dez. 2018 
e melhorias. Diante da busca pela expansão dos lucros era necessário e imperativo a diminuição dos custos da mão de obra. Nesse sentido, enfatiza Ricardo Antunes

a quase totalidade dos países de capitalismo avançado viu decrescer os empregos em tempo completo e assistiu a um aumento explosivo das formas de subproletarização, por meio da expansão dos trabalhadores parciais, precários, subcontratados etc., tanto no setor produtivo, como no de serviços (ANTUNES, 1997, pág. 34-35).

Assim, viram-se emoldurados os direitos fundamentais na bela Carta Magna Cidadã de 1988, porém em grande parte longe da realidade dos trabalhadores brasileiros. Esse distanciamento entre o mundo normativo e o mundo real não poderia resultar em outro fenômeno que não seja a crise de efetividade dos direitos sociais do trabalhador. A força do modelo econômico prevaleceu diante do que se desenhara para os direitos sociais, mormente o ideal progressista impresso no caput do art. $7^{\circ}$ da $\mathrm{CF} / 88$.

Não obstante, a partir do início do século XXI, parecia que os rumos da história da concretização dos direitos do trabalhador ganhariam outros capítulos. Embora comprometido com o modelo econômico, concomitantemente, iniciou-se um momento de efetivação de direitos sociais. $\mathrm{O}$ desenvolvimento e o crescimento econômico, unidos às políticas públicas de distribuição da renda, propiciaram a ascensão das classes menos favorecidas.

Aumentou-se, consideravelmente, o número de trabalhadores com CTPS assinada, segundo o IBGE (Instituto Brasileiro de Geografia e Estatística), na composição da população ocupada total em 2012, os empregados com carteira assinada no setor privado representavam $49,2 \%$ do contingente, sendo que as estimativas de 2012, frente às de 2003, revelaram crescimento de 53,6\% (de 7,3 para 11,3 milhões) no contingente desses empregados. Atingimos quase o nível do pleno emprego.

A inclusão social pela melhoria das condições de vida das classes menos favorecidas era uma realidade para parcela significativa da população que saiu da linha da extrema pobreza (segundo estudo do Banco Mundial, 29 milhões de brasileiros saíram da pobreza entre 2003 e 2014). As esperanças renovaram-se.

Porém, a efetividade das promessas constitucionais pouco durou e as exigências do mercado se impuseram de maneira ainda mais feroz que anteriormente, com a chegada ao país dos efeitos da crise capitalista de 2008, que culminou com a flexibilização das normas trabalhistas, visíveis nas alterações legislativas recentes, como a Lei da Terceirização (Lei $\mathrm{n}^{\circ}$ 13.429/2017), permitindo-a de forma ampla e irrestrita, e a alteração de maior impacto, a reforma trabalhista, advinda com a Lei n ${ }^{\circ} 13.467 / 2017$, que no dizer de Delgado trouxe 
[...] as inovações [que] eliminaram, desregulamentaram ou flexibilizaram diversas parcelas trabalhistas de maneira a diminuir, significativamente, o valor trabalho na economia e na sociedade e, em decorrência, o custo trabalhista para o poder econômico. Embora se fale eufemisticamente, em simplificação, desburocratização, racionalização e modernização, além da busca de maior segurança jurídica no contexto da relação empregatícia, o fato é: as inovações, em sua vasta maioria, debilitam, direta ou indiretamente, os direitos e garantias trabalhistas, exacerbam os poderes contratuais do empregador na relação de emprego e diminuem, acentuadamente, os custos da contratação do trabalho humano pelo poder econômico. (DELGADO, 2018, p. 120-121).

Embora verificadas no plano infraconstitucional, em vários aspectos, as alterações demonstram o enfraquecimento da efetividade dos direitos fundamentais dos trabalhadores brasileiros. Veja-se, como exemplo, a revogação do art. 384, da CLT, que assegurava à empregada mulher 15 minutos de intervalo, antes do início da prestação de serviços extraordinários, malferindo nítida norma de proteção à saúde e segurança do trabalho (art. $7^{\circ}$, XXII CF/88).

O trabalho intermitente (art. 452-A da CLT) introduzido pela reforma traz em seu bojo uma receita que pode implicar na possibilidade de um empregado, no final do mês, não alcançar nem o salário mínimo completo, embora formalmente com a CTPS assinada e o salário mínimo hora preservado. Essa espécie de trabalhador percebe somente pelas horas trabalhadas, ou seja, se durante o mês não for convocado para o trabalho, corre o risco de ficar sem rendimento nenhum.

Não menos grave é a chamada tarifação das indenizações por dano moral (art. 223-G, § $1^{\circ}$ e incisos) que desconsiderou toda a construção doutrinária e jurisprudencial já sedimentada. A individualização das indenizações, analisadas as circunstâncias do caso concreto e a busca da preservação dos valores intrínsecos a cada pessoa e sua dignidade sempre foram os principais fundamentos da rejeição da atribuição de indenização fixa e tarifada nas ações de dano moral.

A despeito dos ensinamentos kantianos, a reforma, nesse aspecto, pareceu caminhar para a mercantilização da força de trabalho. Pretendeu conferir um preço fixo ao valor moral humano, a pretexto de limitar importes indenizatórios considerados excessivos e imprevisíveis, de modo que não se ofereça maiores riscos econômicos e se preserve o lucro. Nessa esteira, a dignidade do trabalhador que, caso tenha seu direito de personalidade violado, é secundarizada, pois se resolve a lide com atribuição de um preço fixo, independentemente das circunstâncias e das condições pessoais dos envolvidos. A força de trabalho é utilizada como um mero instrumento a serviço do capital.

Sem embargo, há importantes direitos que sequer foram regulamentados, a exemplo da 
fundamental proteção contra despedida arbitrária ou sem justa causa (art. $7^{\circ}$, I, da CF/88). No ano em que a Constituição completa 30 anos. a lei complementar exigida para regulamentar a matéria ainda aguarda por promulgação. A omissão legislativa permite uma enorme rotatividade da mão de obra, insegurança e instabilidade, pois possibilita ao empregador rescindir o contrato de trabalho (em regra, única fonte de subsistência do trabalhador) de forma unilateral e sem qualquer justificativa, desde que assuma o singelo ônus financeiro que a modalidade da despedida impuser. Em outras palavras, após trinta anos de previsão do direito, basta a vontade (ou má) do patrão e o trabalhador perde sua fonte de renda e sustento, sem maiores consequências.

Assim, os exemplos mencionados, sejam os decorrentes da reforma, sejam os que padecem de regulamentação infraconstitucional, indiciam o tratamento secundário conferido ao valor trabalho, embora não o seja em termos de opção constitucional (art. $1^{\circ}$, IV, CRFB/88). O rol de direitos elencados, essencialmente, nos artigos $7^{\circ}$ ao 11 da CRFB/88 perdem densidade diante das omissões e transformações na legislação infraconstitucional que acabam por representar a vitória dos ideais neoliberais, marcados pela intensa e agressiva política financeira de desregulamentação de direitos e intervenção mínima do Estado.

Como anteparo à onda liberalizante, ganhou densidade o princípio da vedação ao retrocesso social que, embora não expresso na Constituição, decorre dos Tratados Internacionais firmados pelo Brasil, como o Pacto Internacional sobre Direitos Econômicos, Sociais e Culturais de 1966 e a Convenção Americana de Direitos Humanos de 1969 (Pacto de San José da Costa Rica).

A vedação do retrocesso, por fim, é uma derivação da eficácia negativa,
particularmente ligada aos princípios que envolvem os direitos fundamentais. Ela
pressupõe que esses princípios sejam concretizados através de normas
infraconstitucionais (isto é: frequentemente, os efeitos que pretendem produzir são
especificados por meio da legislação ordinária) e que, com base no direito
constitucional em vigor, um dos efeitos gerias pretendidos por tais princípios é a
progressiva ampliação dos direitos fundamentais (BARROSO, 2005, p. 44).

A imposição do princípio da vedação ao retrocesso se deve ao descompasso entre as iniciais previsões normativas ofertadas e as constantes contradições/alterações contrárias a esses postulados. $\mathrm{O}$ ideal de justiça social pressupõe a manutenção do mínimo existencial e a permanente concentração de renda, o alto índice de desemprego e subemprego são fatores imperiosos a necessidade de sua defesa.

Não se olvida que o mundo passou por grandes mudanças: inovações tecnológicas, globalização, expansão dos mercados, rompimento das fronteiras alfandegárias, sucessivas 
crises do capitalismo, transferência da produção para países periféricos, que culminaram em transformações dos objetivos e da própria maneira de viver e pensar da sociedade. No entanto, tais mudanças não podem justificar a diminuição de um patamar básico de direitos para garantia de uma vida digna. Sem valorização do ser humano trabalhador, sem agregar valor ao seu trabalho, caminha-se para o retorno a estágios precários nas relações de trabalho, inconcebíveis para um Estado que tem como centralidade a pessoa humana e o respeito à dignidade.

A evolução social não pode ser esvaziada em nome da prevalência de políticas econômicas, marcadamente voltadas em atender aos interesses do mercado capitalista. São necessárias medidas de contenção da agressividade voraz do capital e o princípio da vedação ao retrocesso pode funcionar como uma cláusula de contenção, a fim de garantir as conquistas de outrora. Se assim não o for, estaremos a validar a mercantilização do outro, pretensão de muitos que insistem no sucesso do modelo concentrador de riqueza, porém inconcebível no atual estágio da humanidade.

A construção do Estado Social Democrático de Direito exige compromisso em sentido contrário a permear os setores da sociedade civil e da política, bem como os Poderes da República, responsáveis pela implementação de políticas públicas, capazes, de fazer valer a força normativa da constituição.

Embora a luta pela não retirada de direitos trabalhistas e defesa de vedação ao retrocesso social pareça uma quimera, quando o necessário para uma vida digna sequer foi alcançado, considerando que o salário mínimo, atualmente no valor de $\mathrm{R} \$ 954,00$, nem de longe é capaz de atender as necessidades vitais básicas do trabalhador e de sua família com moradia, alimentação, educação, saúde, lazer, vestuário, higiene, transporte e previdência social (art. $7^{\circ}$, IV, da CRFB/88), ela se impõe como um bastião neste momento de desmantelamento dos direitos sociais do trabalhador.

A permanecer o caminho trilhado até o momento, os direitos fundamentais trabalhistas garantidos constitucionalmente e capazes de elevar o patamar de civilidade de uma nação, tornar-se-ão letra morta, ou melhor, não passarão de uma simples moldura, sem qualquer relevância no meio social. Portanto, a reforma promove distanciamento entre as normas constitucionais e a realidade social de modo a cristalizar a Constituição brasileira como Constituição simbólica (NEVES, 2007), álibi para manter o status quo. Efetivamente, haverá ampliação dos espaços vazios de constitucionalismo em decorrência da proteção social meramente nominal do trabalhador brasileiro. Por corolário, os demais direitos fundamentais restarão comprometidos, dada a inevitável relação existente entre si. 


\begin{abstract}
Vale dizer, sem a efetividade dos direitos econômico, sociais e culturais, os direitos civis e políticos se reduzem a meras categorias formais, enquanto, sem a realização dos direitos civis e políticos, ou seja, sem a efetividade da liberdade entendida em seu mais amplo sentido, os direitos econômicos e sociais carecem de verdadeira significação . Não há mais como cogitar da liberdade divorciada da justiça social, como também infrutífero pensa na justiça social divorciada da liberdade. Em suma, todos os direitos humanos constituem um complexo integral, único e indivisível, em que os diferentes direitos estão necessariamente inter-relacionados e interdependentes entre si. (PIOVESAN, 1998, p. 138-139).
\end{abstract}

Assim, a falta de concretização dos direitos fundamentais sociais, nestes inclusos os trabalhistas, tem implicação na efetividade de outros direitos fundamentais, os civis e políticos e, por consequência, na própria cidadania e democracia. Não sem razão ou substancialidade. Como se poderá falar em pleno exercício de direitos civis sem a garantia de um trabalho que assegure o mínimo para preservar a dignidade? Poderá um trabalhador por anos vivendo em condições análogas à de escravo falar em cidadania?

No mundo moderno capitalista, o trabalho passou a ser o locus do indivíduo e, até mesmo, um fator de identidade. Nos apresentamos como pessoas para em seguida sermos engenheiros, bancários, pedreiros, motoristas, etc. A vida contemporânea gira em torno do trabalho, como fator dignificador do homem. Portanto, o fator trabalho e os direitos dele decorrentes são indispensáveis ao pleno exercício da cidadania. Diante desse quadro, a questão da efetividade dos direitos constitucionais trabalhistas, torna-se crucial e merece maior atenção das comunidades jurídica e política, sob pena de uma meia existência, de uma vida sem a plenitude do indivíduo.

\title{
4. PERSPECTIVAS
}

O cenário trazido pela reforma trabalhista é pautado no desmonte dos pressupostos basilares protetivos do Direito do Trabalho. A premissa elementar baseia-se na paridade entre empregado e empregador, quando se sabe que a realidade econômica confere supremacia a este último, pois o empregado tem no posto de trabalho sua fonte de subsistência.

As normas de proteção ao trabalho são uma conquista da civilização, dado o evidente desequilíbrio entre os contratantes, de modo que se fazia necessário a superação do pacta sunt servanda e a necessidade de que o estado interviesse a fim de promover o reequilíbrio, como bem esclareceu Américo Plá Rodriguez "Historicamente, o Direito do Trabalho surgiu como consequência de que liberdade de contrato entre pessoas com poder e capacidade econômica 
desiguais conduzia a diferentes formas de exploração"(RODRIGUES, 1993, p. 30).

As normas protetivas, vigas mestras do Direito do Trabalho e razão de sua própria existência, cederam em parte às diversas pressões que o mercado capitalista e a doutrina neoliberal impuseram, a pretexto do frágil discurso de retomada do crescimento econômico e geração de novos empregos.

\begin{abstract}
Não obstante a inegável força e os amplos recursos midiáticos dessa matriz ideológica unilateral (o chamado neoliberalismo ou ultraliberalismo), ela não possui, conforme se sabe, caráter absoluto. Afinal, é manifesto o substrato de interesses econômicos que responde pela existência e veiculação dessa matriz, supondo profunda ingenuidade do destinatário que se deixe influenciar por semelhante ideário propagandístico. Além disso, têm sido reiterados os exemplos da ineficiência prática das medidas mercantilizadoras propostas por esse ideário, responsáveis não apenas pela acentuação e repetição de crises econômicas ao longo do globo, como também pelo aprofundamento da exclusão e diferenciação social em vários países submetidos à sua mais direta influência (DELGADO, 2018, p. 91).
\end{abstract}

O Estado, que sempre teve um papel relevante nesta relação desigual, na medida que emanava normas justamente na tentativa de amenizar a assimetria existente, propositadamente, deixa os trabalhadores à própria sorte, como se fosse possível falar em sorte, diante da renúncia que a necessidade imediata por emprego impõe. No entanto, a razão de ser do Estado é justamente a pessoa humana, como acentua Ingo Sarlet “[...] categoricamente que é o Estado que existe em função da pessoa humana, e não o contrário, já que o ser humano constitui a finalidade precípua, e não meio da atividade estatal (SARLET, 2006, p.65)”. Assim, a omissão casuística que se visualizou com as últimas alterações legislativas nos leva a refletir até mesmo sobre o papel do Estado como principal agente concretizador dos direitos fundamentais do trabalhador.

Dentre as modificações que denunciam a retirada do estado interventor das relações laborais, cite-se o art. 611-A da CLT, introduzido com a reforma trabalhista de 2017, que confere prevalência às convenções e acordos coletivos de trabalho sobre o legislado, quando dispuserem sobre plano de cargos e salários, jornada de trabalho, intervalo intrajornada, banco de horas, prorrogação de jornada em ambientes insalubres, sem licença prévia das autoridades competentes do Ministério do Trabalho, enquadramento do grau de insalubridade, dentre outras hipóteses enumeradas sem seus incisos. Referida disposição poderia denotar um avanço ao colocar sob a responsabilidade dos sindicatos os rumos das relações laborais, contudo é certo que não somos um país de associações fortes e com poder de imprimir pressão eficaz no patronato.

Com efeito, mesmo diante da grande quantidade de agremiações sindicais e a permanência da unicidade sindical, menos de $20 \%$ dos empregados são sindicalizados e a 
maioria dos não sindicalizados desconhece qual entidade representa sua categoria, conforme aponta pesquisa do IBGE que analisa aspecto da relação de trabalho e sindicalização no país, sinalizando a grande dimensão da falta de representatividade das entidades sindicais nacionais. A propósito das limitações que o sindicalismo ainda mantém, fruto do modelo corporativista implantado à época do Estado Novo (1937-1945), e as consequências para defesa dos associados, tem-se que:

[...] essas restrições são as grandes responsáveis por aprisionar os trabalhadores em uma atrasada, monopolística, autoritária e ineficaz forma de organização, e que faz com que sejam tutelados por entidades fracas e dirigentes não comprometidos, regra geral, além de por outros entes, que ocupam o vazio deixado.

Alterar parte das normas que regulam as relações coletivas de trabalho, como eliminar a contribuição sindical compulsória o que é correto, ou privilegiar o negociado sobre o legislado, respeitados os direitos fundamentais do trabalhador, o que é perfeitamente possível, havendo entidades sindicais fortes, então, não resolverá o problema, e até o agravará, no segundo caso, caso não se ataque o problema onde ele realmente está: a falta da representatividade das atuais entidades sindicais, pressuposto para uma relação mais equilibrada entre os trabalhadores, de um lado, e os empregadores e o estado, conforme o caso, do outro (BRITO FILHO, 2017, p.26).

Esse modelo de sindicalismo é incapaz de representar os trabalhadores e garantir paridade com os empregadores, como propõe a reforma, quando sequer são capazes de responder as mais comezinhas demandas que lhes são postas pelos integrantes da categoria.

O mesmo propósito de redução da intervenção estatal, nas relações de trabalho, verificou-se no parágrafo único do art. 444 da CLT, ao dispor que a livre estipulação das partes nas relações contratuais de trabalho, no caso de empregado portador de diploma de nível superior e que perceba salário mensal igual ou superior a duas vezes o limite máximo dos benefícios do Regime Geral de Previdência Social, aplica-se às hipóteses previstas no art. 611A, com a mesma eficácia legal e preponderância sobre os instrumentos coletivos. A lei pressupõe que com esses dois requisitos se confere ao prestador de serviços poderes para negociar em condições de igualdade com o empregador, mesmo que esteja sob o manto da subordinação jurídica.

Deixar nas mãos dos atores trabalhistas, que não estão em paridade de condições para entabular negociação, os rumos de suas melhorias jurídicas é sinônimo de uma escolha manifesta: a prevalência da parte economicamente mais forte, o que, fatalmente, colocará em risco direitos até mesmo já consolidados. Nem se diga que os empregados que possuem diploma de nível superior e ganham salário mensal duas vezes maior que o teto da previdência social (atualmente $\mathrm{R} \$ 5.645,80$ ) estão em pé de igualdade com seus empregadores, quando se sabe que o poderio econômico e, consequentemente, o de pressão dos patrões, que possuem 
capacidade financeira para remunerar um único empregado com valores ao dobro do teto da previdência, ou seja, $\mathrm{R}$ \$ 11.291.60, são bem mais fortes que a capacidade dos empregados resistirem.

Não se olvida que são empregados esclarecidos, mas a necessidade de manter ou adquirir um emprego, em regra, deixa qualquer pessoa vulnerável, porquanto é cediço que quem somente tem sua força de trabalho para sobreviver, certamente, se submeterá a qualquer condição de trabalho.

Neste contexto, diante da falta de representatividade do sindicalismo no Brasil, mormente com a permanência da unicidade sindical, o que se avizinha nesse embate é o enfraquecimento dos direitos sociais dos trabalhadores. Circunstância previsível, quando o poder de articulação e enfrentamento dos trabalhadores não apresentam a paridade capaz de fazer prevalecer suas reivindicações.

O Estado constitucionalmente apontou seus fundamentos (art. $1^{\circ}$ da CRFB/88, dentre eles a dignidade da pessoa humana e o valor social do trabalho), enumerou seus objetivos (art. $3^{\circ}$ da CRFB/88, a exemplo de construir uma sociedade livre, justa e solidária e reduzir as desigualdades sociais e regionais, bem como promover o bem de todos) e fixou os direitos básicos do trabalhador ( $\operatorname{artigos} 7^{\circ}$ a $11 \mathrm{CRFB} / 88$ ). A atual opção governamental é francamente contraditória com os postulados constitucionais. Essa dissonância caminha para a desconstituição dos pilares democráticos. A relação entre os fundamentos do Estado Democrático de Direito e a efetividade dos direitos sociais, diante das profundas alterações legislativas e a expansão do modelo neoliberal, traz crescente preocupação com o cenário já constituído e com as perspectivas vindouras.

De outra parte, segue sendo necessária uma preocupação permanente com a
consolidação e manutenção pelo menos dos níveis de proteção social mínimos, onde
e quando alcançados, nas várias esferas de segurança social e de tutela dos direitos
sociais compreendidos em toda a sua amplitude, inclusive como condição para a
funcionalidade da própria democracia e sobrevivência do Estado Constitucional.
(SARLET, 2009, p. 120-121).

O momento é de alerta, pois as reduções e supressões que antes eram meras hipóteses, hoje são realidades e com perspectivas de continuidade, se considerarmos que nova reforma se aproxima cujos destinatários são os menos favorecidos, a chamada reforma da previdência, com todas as suas matizes.

O paradoxo é manifesto. As normas constitucionais trabalhistas clamam por completa efetividade há quase trinta anos, com pequeno período de suspiro, mas vivemos um momento de supressão e redução de direitos, alguns deles umbilicalmente ligados aos direitos constantes 
no art. $7^{\circ}$ e seguintes, da CRFB/88.

Como não poderia ser diferente, a reforma já começou a dar resultados. A redução sensível do número de ações trabalhistas é um deles. Os dados apontam que as Varas do Trabalho receberam 836.458 processos de janeiro a junho de 2018 , uma redução de $37,7 \%$, em relação ao mesmo período do ano anterior, quando foram recebidos 1.343.605, conforme dados do Tribunal Superior do Trabalho (TST).

Essa queda poderia erroneamente nos levar a crer que o cumprimento espontâneo das normas trabalhistas aumentou com a reforma, mas é certo que num país de tradição escravocrata e acostumado a subvalorizar sua mão de obra, os números apontam que as barreiras ao exercício do direito de ação, v.g. as novas exigências para a concessão do benefício da gratuidade da justiça (art. $790 \S 3^{\circ}$ e $4^{\circ}$ da CLT), a possibilidade de condenação em custas e execução do respectivo valor (art. 790 e $\S 1^{\circ}$ e $2^{\circ}$ da CLT), o pagamento de honorários periciais, em caso de sucumbência na pretensão objeto da perícia, ainda que beneficiário da justiça gratuita (art. 790B) e a condenação em honorários advocatícios (art. 791-A da CLT) é que tem funcionado como novel empecilho ao ajuizamento de novas ações.

Outro aspecto importante é que um dos argumentos embasadores da reforma, a redução do desemprego e geração de mais de 6 milhões de emprego, nas palavras do então Ministro da Fazenda Henrique Meireles, nem de longe se verificou. Segundo o Instituto Brasileiro de Geografia e Estatística (IBGE), em dezembro de 2017, a população ocupada era de 92, 1 milhões de brasileiros, sendo que os trabalhadores informais (sem CTPS assinada ou por conta própria) representavam $37,1 \%$ do total ou 34, 2 milhões, superando os trabalhadores formais que representavam 33, 3 milhões. Ainda segundo o IBGE, essa é a primeira vez na história que os trabalhadores informais superam os trabalhadores registrados. Atualmente, o Brasil conta com 1,3\% de desempregados a mais que o último trimestre do ano de 2017, ou seja, 1,5 milhão a mais de desempregados no país, o que inclusive levou que as previsões do PIB, pelo Banco Central, fossem revistas para baixo.

Os dados revelam, como medida lógica, o aumento das desigualdades sociais, considerando que os baixos salários e alta rotatividade da mão de obra foram contemplados em vários aspectos pela reforma, como no já mencionado caso do contrato intermitente ( art. 443 da CLT), a supressão das horas in itinere (art. $58 \S 2^{\circ}$ da CLT), o caráter indenizatório da remuneração do intervalo intrajornada ( $71 \S 4^{\circ}$ da CLT), a não incorporação da gratificação percebida por mais de 10 anos (art. $468 \S 2^{\circ}$ da CLT).

Nesse sentido, em entrevista para o Instituto Hunanitas Unisinos, Barbara Vallejos 
Vasquez, afirma

[...] a Reforma naturaliza as desigualdades, ao invés de buscar corrigi-las. Foram criadas diversas modalidades de contrato de trabalho, com diferentes níveis de proteção e acesso a direitos. Ao permitir os contratos intermitentes, a legislação autoriza o pagamento de salários mensais menores que o salário mínimo. O efeito destas "inovações" no mercado de trabalho é a redução do salário médio anual, gerando o empobrecimento de uma grande parcela dos trabalhadores no Brasil.[...]

Os direitos estão se esvaindo, sem resistência ou sem que os atores sociais, principalmente os trabalhadores, tenham a dimensão de seu alcance. A realidade é a crise dos direitos fundamentais sociais, diante das persistentes investidas do mercado econômico, iniciadas com a flexibilização dos direitos trabalhistas e tensionadas a se expandir para outros setores, sendo o próximo alvo, por certo, a previdência. O discurso é encantador, fala-se em desburocratização, em fomentar empregos, em crescimento econômico e renda, mas a realidade é que são palavras ocas, de imenso vazio, usadas como ferramenta do poder econômico para boicotar direitos sociais fundamentais, cujos impactos de imediato já atingem parcela mais carente da população, contribuindo para o aumento da segregação social que historicamente marca o país, em nítido contraponto ao projeto político esculpido da Carta Constitucional.

\section{CONCLUSÃO}

No ano em que a Constituição Federal de 1988 completa 30 anos, não muitos são os motivos para comemoração, principalmente no campo dos direitos sociais trabalhistas por ela prometidos, face as sensíveis alterações legislativas ocorridas, principalmente em 2017. O quadro apresentado difere, substancialmente, do momento da publicação da Carta Cidadã, permeado de esperanças e votos de renovação com a instituição do Estado Democrático de Direito, de plano exposto no caput de seu art. $1^{\circ}$. É certo que a construção deste Estado não se faz apenas pelo reconhecimento escrito no corpo jurídico de uma norma, ainda que saibamos sua relevância. Para que um projeto político, ainda que bem escrito, atinja seus fins, é necessário que haja efetividade de suas normas e, assim, no mundo dos fatos, se alcance sucesso nos objetivos traçados.

Nos caminhos percorridos pela carta constitucional de 1988, conquanto houvesse luta de diversos segmentos da sociedade, o que nos tem acompanhado é a perversa inefetividade das normas constitucionais, com raras exceções. As causas são diversas, mas, certamente, o desinteresse do corpo político, aliado à dominação de setores econômicos estão entre as principais delas, muito mais empenhados em manter seus interesses do que em reduzir as 
mazelas sociais.

No momento atual, poderíamos estar a consolidar direitos e garantias, apontar números que indicassem a redução das desigualdades sociais, celebrar a melhoria das condições de vida, o crescimento de postos de trabalho dignos e decentes. Entretanto, nos debruçamos sobre o exato oposto, a persistência da inefetividade das normas e sua pouca repercussão no meio social com o aprofundamento de redução das garantias sociais, majoradas pela reforma trabalhista de 2017 que, ao eliminar direitos a tempos consagrados, reduzir ou dificultar o acesso a outros, inviabiliza o caráter expansionista constante no caput do art. $7^{\circ}$ da CRFB, além de atingir diretamente a concretização dos direitos expressos nos incisos seguintes.

Sequer foram concedidos à totalidade dos trabalhadores os direitos trabalhistas previstos na Carta Magna e o desmonte da melhoria social no âmbito laborativo verificou-se em 2017 com rapidez ímpar, impedindo, por certo, que muitos trabalhadores alcancem condições dignas de trabalho e, assim, mantenham um patamar de civilidade mínimo. Como não bastasse, antes mesmo de consolidada a reforma trabalhista, já se anunciava a reforma da previdência que, sob o pretexto de redução dos gastos públicos, prenuncia, se concretizada como proposta, mais renúncias aos trabalhadores. O campo social é o primeiro a ser alvo das intemperes que o mercado econômico produz. Em regra, a parte mais carente da população brasileira é a primeira a ser sacrificada, suportando quase que exclusivamente o ônus de decisões políticas e econômicas temerárias.

O ordenamento jurídico não pode prescindir de certa flexibilidade, buscando se adequar às novas realidades socioeconômicas, cujas mudanças são naturais com o porvir dos anos; algumas necessárias para o aperfeiçoamento e progresso da sociedade, porém a proteção aos direitos fundamentais, com a garantia de um mínimo existencial, e a manutenção dos pilares do Estado Democrático de Direito devem ser preservados e não são passíveis de negociação, sob pena de completa inversão valorativa e comprometimento da sua própria legitimidade, pois a razão de ser do Estado é o ser humano, não o contrário.

Portanto, a crise de efetividade dos direitos sociais trabalhistas nada mais é que o retrato da dimensão que um país concede à dignidade de seu povo, ao constituírem importante papel na democracia, considerando que o trabalho é o mais eficaz instrumento de inclusão social e econômica, capaz de conferir sucesso às políticas públicas, direcionadas às melhorias das condições sociais. Não se pode assegurar centralidade à pessoa humana e, corolário, respeito à dignidade, sem oferecer condições de acesso a um trabalho digno e decente. Somente a partir dessa perspectiva, poder-se-á alcançar um sistema justo de distribuição de renda. 
Por essas razões e sua centralidade para o aperfeiçoamento dos pilares da Democracia, a questão da inefetividade dos direitos fundamentais sociais, com destaque na abordagem trabalhista, objeto da presente pesquisa, constitui-se ponto de vulnerabilidade para a solidificação do Estado Democrático de Direito no Brasil.

A premissa de que o alcance do desenvolvimento econômico e a geração de empregos decorreria da flexibilização das normas trabalhistas mostrou-se totalmente equivocada, tratando-se de frágil discurso de que o Direito do Trabalho atua como um entrave ao progresso. O avanço econômico depende da conjunção de diversos fatores, dentre eles, o fortalecimento do mercado consumidor, que ocorre com o aumento da distribuição de renda, diretamente relacionada a melhoria salarial.

Por corolário, a precarização das diversas formas de trabalho e a redução dos direitos trabalhistas tiveram efeitos inversos das propostas que encamparam as políticas de flexibilizações. Os subempregos, o desprestígio ao valor trabalho não poderiam trazer benesses, pois representam um retrocesso, inclusive em termos econômicos, já que a redução do mercado consumidor nacional tem impactos negativos para o aumento dos lucros.

Embora as perspectivas não sejam favoráveis às melhorias sociolaborativas, faz-se necessário envidar esforços para a conscientização de toda sociedade política e civil quanto a correlação da manutenção dos direitos fundamentais do trabalhador com o progresso socioeconômico. É necessário uma conjunção das forças políticas em busca de um pacto para a preservação dos pilares erigidos em 1988.

Após três décadas de publicação da CRFB/88, é necessária a reflexão, acompanhada de reação adequada a fazer valer os direitos e garantias fundamentais, através de implementação de políticas públicas consentâneas com objetivos traçados. As alterações legislativas, que parecem caminhar em sentido contrário, não são suficientes para abandonarmos os fundamentos que nos mantém unidos como nação, em permanente aperfeiçoamento. Não se pode concordar com o desmonte de todo o arcabouço jurídico e principiológico, embasadores da democracia brasileira, desde seus primeiros passos até o estágio atual, pois a opção constitucional é clara e se assenta no respeito a dignidade e na centralidade do homem como fundamento maior do Estado Democrático Brasileiro. 


\section{REFERENCIAS}

ANTUNES, Ricardo. Mundo do Trabalho, Precarização e Desemprego. In: MARQUES, Rosa Maria(org.). Mercado de Trabalho e Estabilização. Cadernos PUC Economia 4. São Paulo: Educ, 1997.

BANCO MUNDIAL. The World Bank In Brazil.Brazil's economic and social progress between 2003 and 2014 lifted 29 million people out of poverty and inequality dropped significantly. Disponível em <http://www.worldbank.org/en/country/brazil/overview $\geq$. Acesso em 31 jul.2018.

BARROSO, Luís Roberto. Temas de Direito Constitucional. Tomo III. Rio de Janeiro: Renovar, 2005.

BRASIL. Constituição da República Federativa do Brasil. Disponível <http://www.planalto.gov.br/ccivil_03/constituicao/constituicaocompilado.htm>. Acesso em 10 jul. 2018.

Consolidação das Leis Trabalhistas. Lei $\mathrm{n}^{\circ}$ 5452/43. Disponível em <http://www.planalto.gov.br/ccivil_03/decreto-lei/del5452.htm $\geq$. Acesso em 16 jul.2018.

IBGE. Aspectos das relações de trabalho e sindicalização. Disponível em $<$ https://biblioteca.ibge.gov.br/index.php/biblioteca-catalogo?view=detalhes\&id=2100326 2 . Acesso em 16 jul.2018.

IBGE. Disponível em < https://agenciadenoticias.ibge.gov.br/agencia-noticias/2012agencia-de-noticias/noticias/19759-desemprego-recua-em-dezembro-mas-taxa-media-do-anoe-a-maior-desde-2012 $\geq$.Acesso em 16 jul.2018.

IBGE.Disponível

em

<https://ww2.ibge.gov.br/home/presidencia/noticias/imprensa/ppts/000000127743041720134 32330149857.pdf $\geq$. Acesso em 31 jul.2018.

Lei no 13.467/2017. Disponível em < http://www.planalto.gov.br/ccivil_03/_ato20152018/2017/lei/113467.htm $\geq$. Acesso em 10 jul. 2018.

TST. Movimentação Processual das Varas 2018. Disponível em <file://C:/Users/59399384268/Downloads/Movimenta\%C3\%A7\%C3\%A3o\%20Processual\% 20VT\%202018.pdf >. Acesso em 16 jul. 2018.

BRITO FILHO, José Claudio Monteiro de. Reforma Trabalhista e Previdenciária: entre o sim e o não. In MARANHÃO, Ney; TUPINAMBÁ, Pedro Tourinho(cord.) O mundo do trabalho no contexto das reformas: análise crítica. Homenagem aos 40 anos da Amatra8. Coordenadores Ney Maranhão e Pedro Tourinho Tupinambá. São Paulo: LTr, 2017.

DELGADO, Maurício; DELGADO, Gabriela. Constituição da República e Direitos Fundamentais: dignidade da pessoa humana, justiça social e direito do trabalho. $4^{\mathrm{a}}$ ed. São Paulo: LTr, 2017. 
DELGADO, Maurício Godinho. Curso de Direito do Trabalho. $17^{\mathrm{a}}$ edição. São Paulo: Ltr, 2018.

HESSE, KONRAD. A Força Normativa da Constituição. Tradução de Gilmar Mendes. Porto Alegre: Sérgio Antônio Fabris Editor, 1991.

KANT, Immanuel. Fundamentação da Metafísica dos Costumes. Tradução de Paulo Quintela. Introdução de Pedro Galvão. Lisboa- Portugal: Edições 70, 2011.

NEVES, Marcelo. A Constitucionalização Simbólica. São Paulo: Martins Fontes, 2a ed. 2007.

OLIVEIRA, Murilo Carvalho Sampaio. Notas sobre a crise do Direito do Trabalho. In: Âmbito Jurídico, Rio Grande, IX, n. 28, abr 2006. Disponível em: <http://www.ambitojuridico.com.br/site/index.php?n_link=revista_artigos_leitura\&artigo_id=987>. Acesso em 02 ago. 2018.

PIOVESAN, Flávia. A Constituição brasileira de 1988 e outros tratados internacionais de proteção do direitos humanos. In: MARCÍLIO, Maria Luiza e outro(coords). Cultura dos Direitos Humanos. São Paulo: LTr, 1998.

RODRIGUEZ, Américo Plá. Princípios de Direito do Trabalho. Tradução de Wagner D. Giglio, São Paulo: LTr, $2^{a}$ ed., 1993.

SARLET, Ingo Wolfgang. Dignidade da pessoa humana e Direitos Fundamentais na Constituição Federal de 1988. 4.ed. Porto Alegre: Livraria do Advogado, 2006.

Notas sobre a assim designada proibição de retrocesso social no constitucionalismo latino-americano. Rev. TST, Brasília, vol. 75, nº 3, jul/setembro 2009.

VASQUEZ, Barbara Vallejos. Instituto Humanitas Unisino. Disponível em $<$ http://www.ihu.unisinos.br/580483-empobrecimento-e-naturalizacao-das-desigualdades-saoas-primeiras-consequencias-da-reforma-trabalhista-entrevista-especial-com-barbara-vallejosvazquez $\geq$. Acesso em 16 jul. 2018. 